\title{
Repetitive Olfactory Exposure to the Biologically Significant Steroid Androstadienone Causes a Hedonic Shift and Gender Dimorphic Changes in Olfactory-Evoked Potentials
}

\author{
Nassima Boulkroune', Liwei Wang', Amy March', Natalie Walker' and Tim JC Jacob*,' \\ 'School of Biosciences, Cardiff University, Cardiff, UK
}

\begin{abstract}
The function of a sensory system is to transduce and relay sensory information in a constant and reproducible manner. However, in the olfactory processing of certain steroids this precept of sensory constancy does not appear to apply. Using threshold testing, psychometrics, and electrophysiological techniques, we investigated the effects of a repetitive exposure protocol on the response to androstadienone. Androstadienone is a steroid found in human secretions that has been widely proposed as a candidate for a human pheromone. The detection threshold, hedonic perception, and evoked potential response all changed following repetitive exposure to androstadienone and not to a control odorant, benzaldehyde. Furthermore, the exposure-dependent changes in evoked potentials exhibited a gender dimorphism in which there were changes in the later components of the evoked potentials specific to women. These components have been associated with cognitive and perceptual operations. This 'learning' to smell a compound found in sweat may be related to biological signaling.

Neuropsychopharmacology (2007) 32, I822-1829; doi:I0.I038/sj.npp. I30I303; published online 24 January 2007
\end{abstract}

Keywords: smell; olfaction; pheromone; electro-olfactogram; olfactory-evoked potential; olfactory event-related potential

\section{INTRODUCTION}

For a sensory system to be effective, there are certain absolute requirements. It must have elements selective for the particular stimulus, these elements must respond rapidly, they should be sensitive to small changes in the input and they must respond reliably and not give spurious information (Barlow, 1982).

Under certain circumstances, the response of the human olfactory system not conform to the latter two criteria. There is a response inconstancy to certain steroids. It was originally thought that, because $40-50 \%$ of adults cannot smell the steroid androstenone, there was a high incidence of specific anosmia to this odorant (Amoore, 1977). The explanation for this observation was that nondetectors were lacking the gene coding for the androstenone receptor. The genetic basis for a specific anosmia was supported by the observation that detection thresholds for androstenone were more similar in identical twins than in dizygotic twins (Wysocki and Beauchamp, 1984). However, Wysocki et al (1989) demonstrated that androstenone-anosmics could be

*Correspondence: Professor TJC Jacob, BIOSI-2, School of Biosciences, Cardiff University, Museum Avenue, Cardiff CFIO 3US, UK, Tel: + 44 292087 4l05, Fax: + 44292087 4l I6, E-mail: jacob@cardiff.ac.uk Received 8 October 2006; revised 13 October 2006; accepted 3 November 2006 sensitized to androstenone by repetitive exposure. Their explanation was that, by analogy to the immune system, exposure to the odorant stimulated the proliferation of a subthreshold number of specific receptor-bearing neurons or the selection of receptor-bearing neurons of higher odor-binding affinity. These authors also suggested a further two explanations: one involving more central changes in the olfactory bulb (new neuronal connections) and the other relying upon a shift in cognitive processes whereby subjects learn to use a more effective test-taking strategy. This latter explanation was deemed unlikely as the changes were specific for androstenone. Three further studies have attempted to localize the changes occurring during this androstenone-sensitization process. First, Yee and Wysocki (2001) found that olfactory nerve transaction in mice before repetitive androstenone exposure did not prevent the process of exposure-induced sensitization, strongly implicating the olfactory epithelium in the changes. Secondly, Mainland et al (2002), by repetitively exposing only one nostril to androstenone and demonstrating enhanced sensitivity when stimulating the contralateral nostril, proposed that the induced detection originated in central components of the olfactory system, although they did not rule out a contribution from the plasticity of peripheral components (ie the olfactory epithelium). The third study, by Wang et al (2004a), demonstrated that the electro-olfactogram (EOG) in response to androstenone 
stimulation, increased following repetitive exposure to androstenone, supporting the notion of peripheral olfactory plasticity.

The induction of olfactory sensitivity in humans was initially restricted to androstenone but recently Jacob et al (2006) extended this to another, related steroid occurring in male (and to a lesser extent female) secretions, androstadienone. Dalton et al (2002) have studied the phenomenon with other unrelated, odorous compounds, and finding that repetitive testing resulted in greatly enhanced sensitivity to benzaldehyde and citralva, concluded that the induction of enhanced olfactory sensitivity was a more general phenomenon. However, their enhanced sensitivity was gender specific, occurring only in women of reproductive age and, furthermore, there were methodological differences, with the emphasis in the Dalton et al (2002) study being on the testing rather than the repetitive exposure.

In this present study, we demonstrate an exposureinduced sensitization to androstadienone in both men and women accompanied by a hedonic shift in perception. Underlying this androstadienone sensitization phenomenon, we found gender-specific changes in the evoked potentials. These changes were specific to the steroids and were not observed with the control odorant benzaldehyde.

\section{METHODS}

\section{Subjects}

Twenty-eight subjects (mean age 21 years 8 months) from the student population of Cardiff University were chosen, and divided into two groups: the androstadienone and the benzaldehyde group. The 14 subjects exposed to androstadienone were screened in order that the least sensitive subjects were chosen. The seven men had a mean age of 21 years 10 months, and the seven women had a mean age of 21 years 11 months. Of the 13 subjects exposed to benzaldehyde, six men had a mean age of 21 years 9 months, and seven women a mean age of 21 years 4 months. Each subject received a cash reward for their participation in the study.

\section{Ethical Approval}

The study conformed to the Declaration of Helsinki (1964). Ethical approval $(\# 01 / 4353)$ for this study was granted by the Bro Taff Health Authority Local Research Ethics Committee (Temple of Peace and Health, Cathays Park, Cardiff, UK). Each subject completed a consent form and medical questionnaire. Exclusion criteria included olfactory dysfunction, allergies, epilepsy, respiratory disease, pregnant women, nursing mothers, and those taking prescription medications or exposed to chemicals on a regular basis in the workplace.

\section{Odorants}

The odorants used were androstadienone (4,16-androstadien-3-one), minimum $98 \%$ pure by thin layer chromatography obtained from Steraloids (cat. no. A0570-000; Newport, RI), amyl acetate (cat. no. A1560; Sigma Chemical
Co., Poole, UK), a substance with an apple/banana-like odor and benzaldehyde (cat. no. 418099; Sigma-Aldrich) a liquid with a cherry/almond odor. The binary androstadienone dilutions were made from a stock solution of $12.3 \mathrm{mM}(0.3 \%$ w/v) in silicone oil (Dow Corning 200/350cSt., Midland, MI), The binary dilutions of amyl acetate and benzaldehyde were made from $4.28 \mathrm{mM}(0.064 \% \mathrm{v} / \mathrm{v})$ and $0.978 \mathrm{mM}$ $(0.01 \% \mathrm{v} / \mathrm{v})$ stock solutions, respectively, in dipropylene glycol. These concentrations were chosen to reflect those used by Wysocki et al (1989) and Dalton et al (2002).

\section{Odor Delivery}

The olfactometer (described in detail by Wang et al, 2002) consisted of a filtered air supply delivery system of narrow tubes, a computer-controlled odor switching device, solenoid valves (Cole Palmer, Bishops Stortford, UK), and a water bath. A constant airflow was delivered to the nostril via a Teflon nasal canula inserted through a self-expanding bung (an Aearo Ear Protector, Stockport, UK) approximately $1.5 \mathrm{~cm}$ into the nostril. The self-expanding bung closes off the stimulated nostril ensuring an unidirectional, constant airflow. The subjects were instructed to breathe through their mouths. Olfactory stimulation was achieved using computer-controlled valves to direct part of the airflow into either the odorant-containing reservoirs without altering the pressure or flow rate. The concentrations of androstadienone, amyl acetate, and benzaldehyde in the reservoirs were $12.3,4.28$, and $0.98 \mathrm{mM}$, respectively. The switching mechanism was designed in such a way that during stimulation odorant pulses of pre-established concentrations (diluted 1:3 with humidified air) reached the olfactory region without altering the flow rate thus reducing the chances of trigeminal activation, and during the interstimulus intervals (ISI) only nonodorous control air reached the nose.

On each test occasion, 120 pulses of the odor stimulants were presented at regular ISI of $2.5 \mathrm{~s}$, with a stimulus duration of $200 \mathrm{~ms}$ at a flow rate of $31 / \mathrm{min}$ to one nostril. The temperature of the air flowing into the nostril was regulated to $28.5^{\circ} \mathrm{C}$ by passing it through a coil immersed in a water bath. The relative humidity was maintained at $80 \%$ by passing the continuous air stream through a small glass reservoir containing water.

\section{Repetitive Exposure Trial (Sniff-Training)}

The 14 subjects in the androstadienone group were given a $20-\mathrm{ml}$ bottle containing $0.5 \mathrm{ml} \quad 0.3 \%$ androstadienone and were required to sniff it for 3 min three times daily for 2 weeks. They had their detection thresholds for androstadienone, and the control odor amyl acetate, tested before and after the completion of the repetitive exposure trial (14 days).

The 13 subjects in the benzaldehyde group were given a $20-\mathrm{ml}$ bottle containing $0.5 \mathrm{ml} 0.01 \%$ benzaldehyde and were required to sniff it for $3 \mathrm{~min}$ three times daily for 2 weeks. Their thresholds for benzaldehyde, and the control odor amyl acetate, were tested before and after completion of the repetitive exposure trial (14 days). 
Table I Odorant Descriptors Used to Characterize the Two Test Odors, Benzaldehyde and Androstadienone, before and after 'Sniff-Training'

\begin{tabular}{|c|c|c|c|c|c|}
\hline Putrid & Vegetable & Floral & Woody & Minty & Fruity \\
\hline Sweaty & Green pepper & Rose & Pine & Wintergreen & Lemon \\
\hline Urine & Cucumber & Lavender & Cedar & Peppermint & Orange \\
\hline Rancid & Celery & Violet & Sandalwood & Camphor & Strawberry \\
\hline Sour & Green bean & Lilac & Hickory (barbeque) & Eucalyptus & Cherry \\
\hline Faecal & Cabbage & Muguet (lily) & Balsam & Menthol & Melon \\
\hline \multirow[t]{2}{*}{ Musky } & Cut grass & Jasmine & Straw & Cloves & Banana \\
\hline & & & & & Pear \\
\hline Other (specify) & Other & Other & Other & Other & Other \\
\hline
\end{tabular}

Modified from Stevens and O'Connell (1995).

\section{Odor Descriptors}

Before and after the repetitive exposure trial (sniff-training), the subjects were asked to provide descriptors for the first dilution of the odorants used in their trial; androstadienone and amyl acetate, or benzaldehyde and amyl acetate. Descriptors were selected from Table 1 (modified from Stevens and O'Connell, 1995).

\section{Threshold Test}

The single staircase protocol (Doty and Laing, 2003) was used to determine detection thresholds. This involved a three-alternative forced choice test of an ascending series of 20 binary dilutions. Starting at a low concentration, the odors were presented in an ascending order in $250 \mathrm{ml}$ glass bottles containing $20 \mathrm{ml}$ of liquid. Each odor concentration was presented along with two blanks containing the diluent. When the subject correctly identified the bottle containing the odor twice the staircase was reversed. The average of the last three of six staircase reversals was taken as the threshold.

\section{Electrophysiological Recording}

During the experiment, the subjects were seated in a comfortable chair. They wore headphones through which white noise was played to eliminate auditory cues.

\section{(1) Electro-Olfactogram}

The electro-olfactogram (EOG) was recorded using an electrode placed on the left side of the bridge of the nose, a site referred to as the nasion or N1 (Wang et al, 2004b). The electrode was connected to the input of an optically isolated amplifier (CED1902, Cambridge Electronic Design, Cambridge, UK) and referred to linked mastoids (A1 and A2 according to the international 10/20 system; linked via buffer amplifiers). The filtering was set from DC (high pass), to $200 \mathrm{~Hz}$ (low pass) and a notch filter at $50 \mathrm{~Hz}$ was used.

\section{(2) Olfactory Event-Related Potentials}

Olfactory event-related potentials (OERPs) were recorded using optically isolated amplifiers (CED1902, CED, Cam- bridge, UK) as described previously (Wang et al, 2002). Electrodes were placed according to the international 10/20 system referred to linked mastoids (A1 and A2, see above) and an earth electrode was placed on the forehead. Filtering was as for the EOG (see above). Only data from the vertex $\left(C_{z}\right)$ are reported in this study. Traces contaminated with eye movement artefacts were discarded.

Analog data from all channels were sent to a laboratory interface (CED1401), digitized at $100 \mathrm{~Hz}$ and analyzed following signal averaging on a computer using 'Signal' analysis software (CED, Cambridge, UK).

\section{Statistics}

Data are presented as means \pm SE. Data were tested for normality using the Kolmogorov-Smirnov test and the appropriate nonparametric or parametric tests were used as indicated. The alpha level was 0.05 for all tests.

\section{RESULTS}

\section{Thresholds}

A group of 14 subjects underwent a 'sniff-training' protocol, consisting of a repetitive exposure protocol (see Methods), during which they sniffed androstadienone for $3 \mathrm{~min}$ three times daily for 2 weeks. Their detection thresholds for the steroid were determined before and after training by a three alternative forced-choice test of a series of binary dilutions from a stock of $12.3 \mathrm{mM}$. Unlike many other odorants, thresholds for this steroid are not normally distributed in the general population (Jacob et al, 2006) necessitating nonparametric data analysis. The median detection thresholds were 0.22 and $0.32 \mathrm{mM}$ for women $(n=7)$ and men $(n=7)$, respectively. Following the repetitive exposure protocol, these median thresholds decreased significantly (Wilcoxon's signed ranks test) to 0.033 and $0.088 \mathrm{mM}$ for women $(p=0.018)$ and men $(p=0.018)$, respectively (Figure 1e). There was no significant difference in the degree of sensitization between women and men (Friedman test, $p=0.341$ ).

The detection thresholds for a control odorant, amyl acetate, were normally distributed and remained constant for the women and men, before $(7.2 \pm 3.1$ and $29.3 \pm 15.4 \mu \mathrm{M})$ 


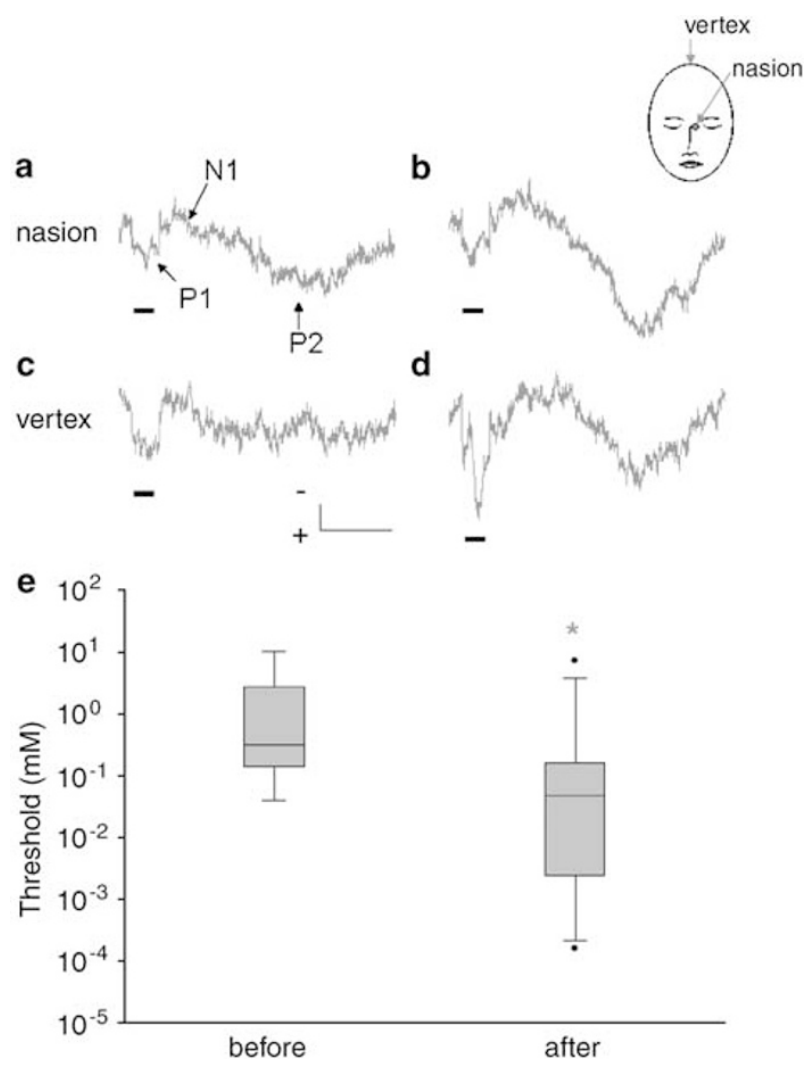

Figure I Androstadienone sensitisation. (a)-(d) Ensemble averages of evoked potentials from 10 subjects ( $5 \mathrm{~F}$ and $5 \mathrm{M}$ ) in response to androstadienone stimulation recorded before (a), (c), and after (b), (d) sniff-training with androstadienone, at the nasion (see inset diagram) (a), (b), and at the vertex (c), (d). The peaks are labeled as follows; first positive peak, PI, first negative peak, NI, and second positive peak, P2. The PINI component of the evoked potential refers to the amplitude from the first positive peak to the first negative peak and NIP2 is the amplitude from the first negative to the second positive peak as indicated. The solid bar indicates the $200 \mathrm{~ms}$ pulse of androstadienone and the scale bar represents $2 \mu \vee$ (vertical) and $500 \mathrm{~ms}$ (horizontal) — clinical neurophysiological convention is followed and upward deflection is negative. The box plots (e) represent the median detection thresholds concentration (mM) for androstadienone before and after sniff-training with androstadienone for men and women combined $(n=14)$. Androstadienone thresholds were not normally distributed (see the text). The box indicates the interquartile range, the whiskers give the range and dots are outliers. ${ }^{*} p<0.05$.

and after $(7.8 \pm 2.4$ and $21.5 \pm 7.7 \mu \mathrm{M})$ the androstadienone sniff-training.

\section{Evoked Potentials}

The olfactory-evoked potentials recorded both at the nasion and vertex increased during this sensitization period (Figure 1a-d). The first positive peak (clinical neurophysiological convention, positive deflections downward) is referred to as $\mathrm{P} 1$ and the first negative peak as $\mathrm{N} 1$ etc. At the nasion the amplitude, measured from the initial positive peak to the first negative peak (P1N1) and calculated from the mean of the individual traces, increased significantly $(p=0.042$; $t$-test) from $3.8 \pm 0.4$ to $4.4 \pm 0.6 \mu \mathrm{V}$ (mean $\pm \mathrm{SE}$, $n=10)$ and from $4.9 \pm 0.4$ to $6.6 \pm 0.8 \mu \mathrm{V}(p=0.004)$ at the vertex. Although the N1P2 component (peak of first

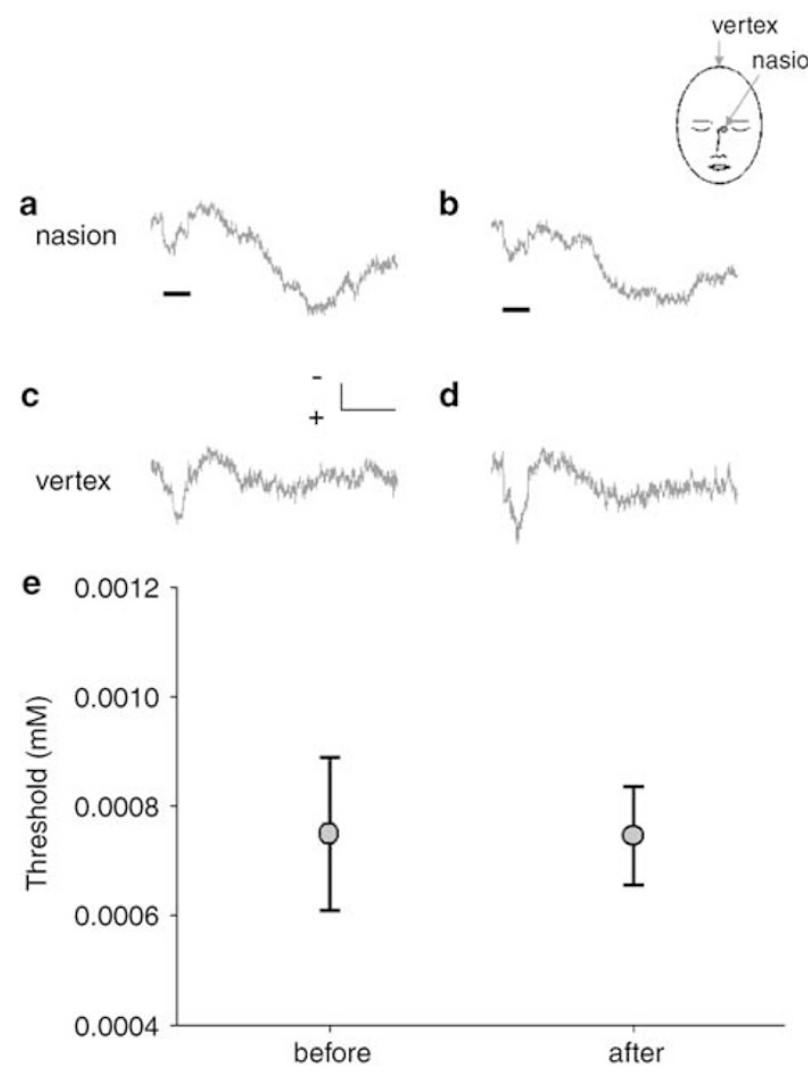

Figure 2 Benzaldehyde responses. (a)-(d) Ensemble averages of evoked potentials from 10 subjects ( $5 \mathrm{~F}$ and $5 \mathrm{M}$ ) in response to benzaldehyde stimulation recorded before (a), (c), and after (b), (d) sniff-training with benzaldehyde, at the nasion (see inset diagram) (a), (b), and at the vertex (c), (d). The solid bar indicates the 200 ms pulse of benzaldehyde and the scale bar represents $2 \mu \mathrm{V}$ (vertical) and $500 \mathrm{~ms}$ (horizontal). (e) The detection thresholds $(\mathrm{mM})$ for benzaldehyde (mean \pm SEM) before and after sniff-training with benzaldehyde for men and women combined. No significant changes were observed.

negative to second positive peak) increased significantly ( $p=0.042, t$-test) from $4.9 \pm 0.9$ to $8.4 \pm 2.2 \mu \mathrm{V}$ at the nasion and from $4.9 \pm 0.4$ to $5.8 \pm 0.9 \mu \mathrm{V}$ at the vertex, this latter increase was not significant owing to the gender differences in the response (see below).

\section{Controls}

A parallel group of 13 subjects (seven women and six men) followed the same 'sniff-training' protocol but, instead of androstadienone, used benzaldehyde. The mean benzaldehyde detection thresholds for women and men were normally distributed and were the same, 0.75 and $0.746 \mu \mathrm{M}$, respectively, and did not change following 'sniff-training' ( $t$-test; benzaldehyde detection thresholds are normally distributed (Kolmogorov-Smirnov test), $p=0.545$; see Figure 2e). Similarly, there were no significant differences in the evoked potentials recorded at the nasion or the vertex before or after sniff training (Figure 2a-d).

The detection thresholds for amyl acetate, tested at the same time, remained constant for women and men, before $(13.1 \pm 3.1$ and $11.8 \pm 3.6 \mu \mathrm{M})$ and after $(12.6 \pm 3.6$ and $12.3 \pm 3.5 \mu \mathrm{M})$ the benzaldehyde sniff-training. 

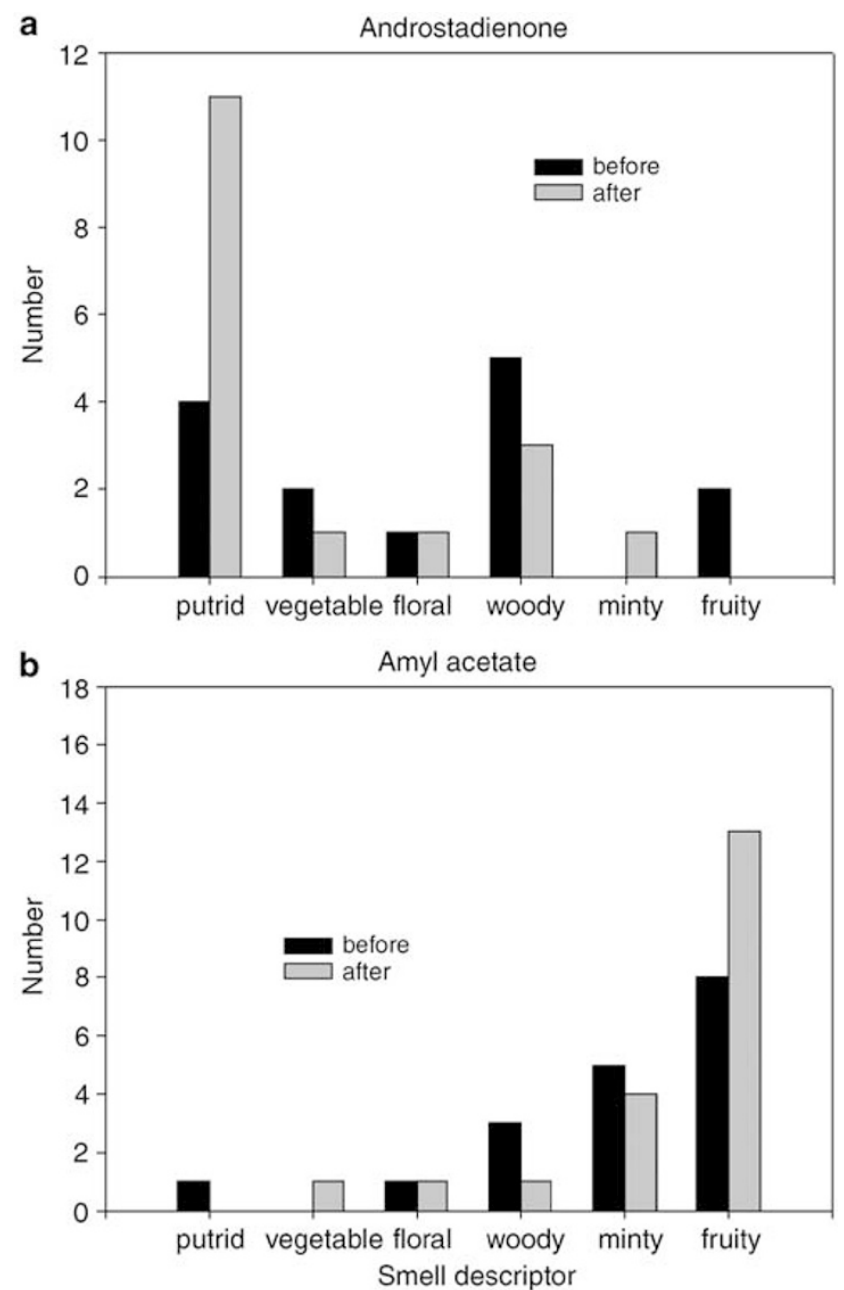

Figure 3 (a) Androstadienone descriptors. Smell descriptors for androstadienone selected by the subjects $(n=14)$ from Table I before and after sniff-training with androstadienone. The descriptors changed, significantly from pleasant to unpleasant following sniff-training $\left(\chi^{2}=4.604\right.$, corrected for $2 \times 2$ table, $p=0.032$ ). (b) Benzaldehyde descriptors. Smell descriptors for benzaldehyde selected by the subjects $(n=13)$ from Table I before and after sniff-training with benzaldehyde. The descriptors did not change significantly.

\section{Odor Descriptors}

Before and after sniff-training, all subjects were asked to choose descriptors from a list (Table 1). These were condensed to six main categories; putrid, vegetable, floral, woody, minty, and fruity. Whereas the descriptions of benzaldehyde remained fairly constant (fruity), those of androstadienone changed significantly $\left(\chi^{2}=4.604\right.$, corrected for $2 \times 2$ table, $p=0.032$ ) in the direction nonputrid (pleasant) to putrid (unpleasant) (Figure 3 ).

\section{Gender Differences with Androstadienone}

The evoked potential response to androstadienone showed marked gender dimorphism. Figures $4 a-d$ and $5 a-d$ show the ensemble averages before and after androstadienone sniff-training. There was a large, statistically significant gender difference between the waveforms recorded at both the nasion and the vertex (two-way between-subject

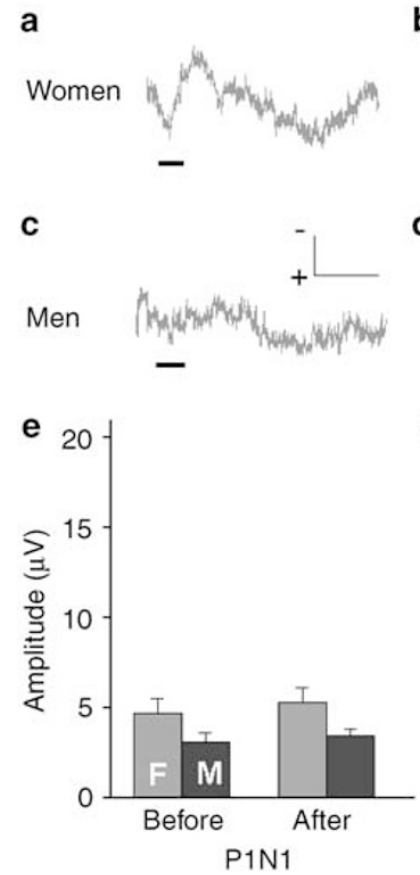

b

d
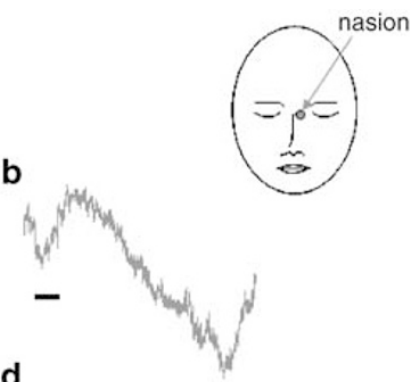

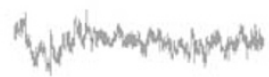

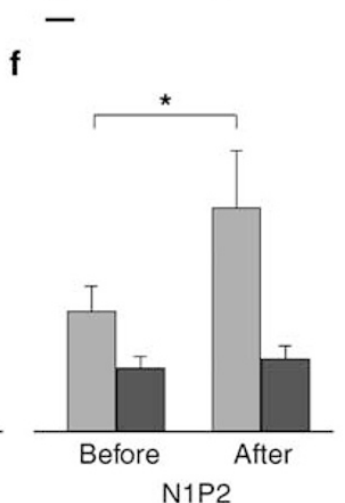

Figure 4 Androstadienone EOG. Ensemble averages of evoked potentials recorded from the nasion (see inset diagram) in women $(n=5)$ and men $(n=5)$, in response to androstadienone stimulation recorded before ( $a$ and $c$ ) and after ( $b$ and $d$ ) sniff-training with androstadienone. The solid bar indicates the $200 \mathrm{~ms}$ stimulus pulse of androstadienone and the scale bar represents $2 \mu \mathrm{V}$ (vertical) and $500 \mathrm{~ms}$ (horizontal) - clinical neurophysiological convention is followed and upward deflection is negative. The histograms represent the averages of the amplitudes of PINI (e) and NIP2 (f) of individual responses from women and men before and after sniff-training. There were significant (*) gender differences and the evoked potentials increased following sniff training (for details see the text).

analysis of variance (ANOVA) $(\mathrm{F}(1,9)=10.17, p=0.011$, $\left.\eta^{2}=0.531\right)$ ) before sniff-training which increased following the training $\left(\mathrm{F}(1,9)=20.032, p=0.002, \eta^{2}=0.690\right)$.

The averages (normally distributed, KolmogorovSmirnov tests $p$-values $=0.146-0.200)$ of individual responses were determined before and after sniff-training, and are plotted as histograms (Figures 4e, f and 5e, f). Following sniff-training there were increases in the amplitudes that were much more pronounced in women than in men. In women, the P1N1 nasion response (Figure $4 \mathrm{a}$ and $\mathrm{b}$ ) increased $12 \%$ ( $t$-test $p=0.024), P 1 N 1$ recorded at the vertex (Figure $5 \mathrm{a}$ and $\mathrm{b})$ increased $42 \%(p=0.046), \mathrm{N} 1 \mathrm{P} 2$ at the vertex (Figure $5 \mathrm{a}$ and $\mathrm{b}$ ) increased $40 \%(p=0.0424)$, but the largest increase $(86 \%, p=0.0254)$ was in N1P2 recorded at the nasion (Figure $4 \mathrm{a}$ and $\mathrm{b}$ ). In men, the only significant increase $(27 \%, p=0.0025)$ was in $\mathrm{P} 1 \mathrm{~N} 1$ recorded at the vertex (Figure $5 \mathrm{c}$ and $\mathrm{d}$ ).

\section{Benzaldehyde}

There were gender differences to benzaldehyde for the N1P2 component of the evoked response recorded at the vertex; 


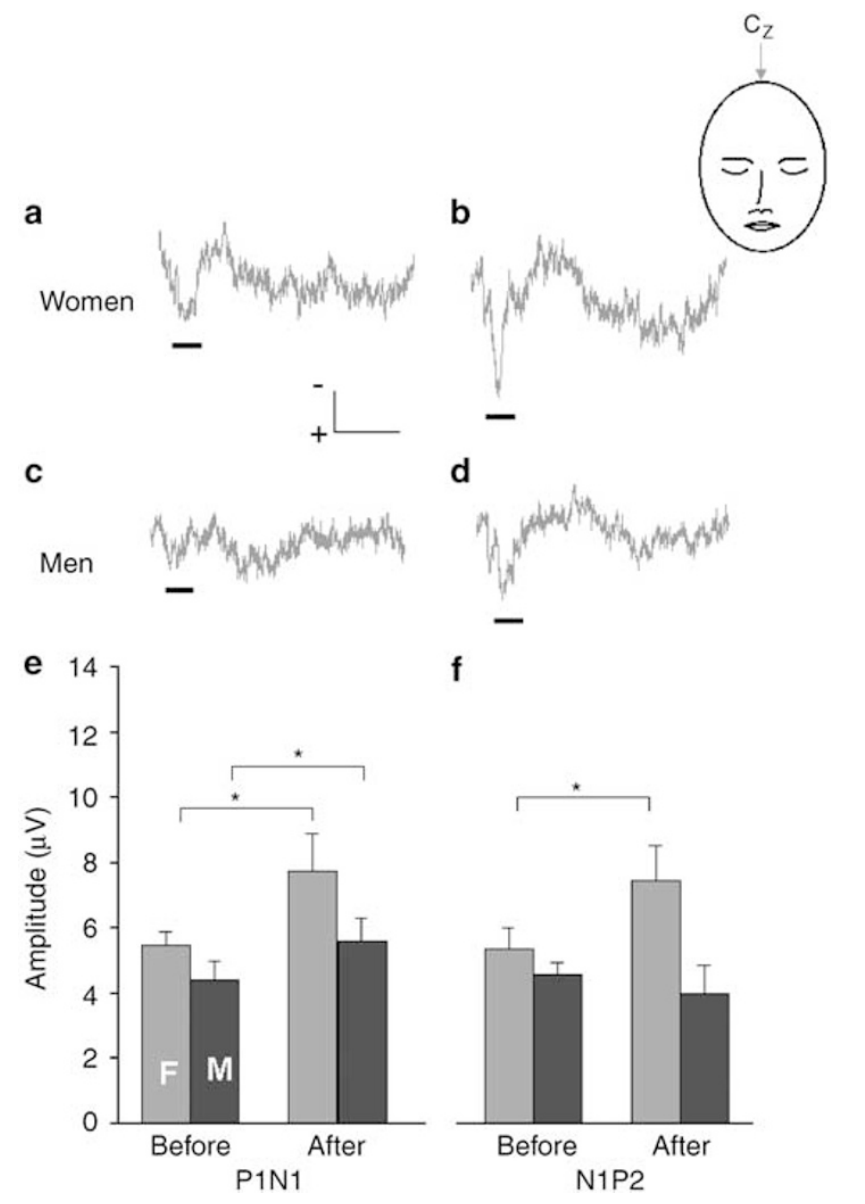

Figure 5 Androstadienone OERP. Ensemble averages of evoked potentials recorded from the vertex (see inset diagram) in women $(n=5)$ and men $(n=5)$, in response to androstadienone stimulation recorded before ( $a$ and $c$ ) and after ( $b$ and $d$ ) sniff-training with androstadienone. The solid bar indicates the $200 \mathrm{~ms}$ stimulus pulse of androstadienone and the scale bar represents $2 \mu \mathrm{V}$ (vertical) and $500 \mathrm{~ms}$ (horizontal) - clinical neurophysiological convention is followed and upward deflection is negative. The histograms represent the averages of the amplitudes of PINI (e) and NIP2 (f) of individual responses from women and men before and after sniff-training. There were significant (*) gender differences and the evoked potentials increased following sniff training (for details see the text).

women $=7.3 \pm 1.0 \mu \mathrm{V}$, men $=4.2 \pm 0.4 \mu \mathrm{V} \quad$ (means $\pm \mathrm{SE}$ of individual responses; $t$-test, $p=0.015$ ) (Figure $7 \mathrm{~b}, \mathrm{~d}$, and f). The other components were the same for women and men; at the nasion, $\mathrm{P} 1 \mathrm{~N} 1=5.0 \pm 0.9 \mu \mathrm{V}$ and $\mathrm{N} 1 \mathrm{P} 2=9.7$ $\pm 2.0 \mu \mathrm{V}$ (Figure 6) and at the vertex $\mathrm{P} 1 \mathrm{~N} 1=6.6 \pm 0.7 \mu \mathrm{V}$ (Figure 7). There were no significant changes following sniff-training with benzaldehyde (two-way ANOVA, $\mathrm{F}(1,16)=$ $1.379, p=0.257)$.

\section{DISCUSSION}

In this study, we investigated the physiological changes accompanying the exposure-dependent sensitization to the steroid androstadienone and correlated them with the concurrent perceptual changes. Evoked potentials were recorded at two sites, the vertex and the bridge of the nose, referred to as the nasion. The response recorded at the

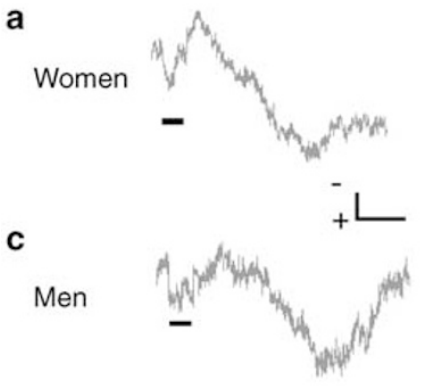

b
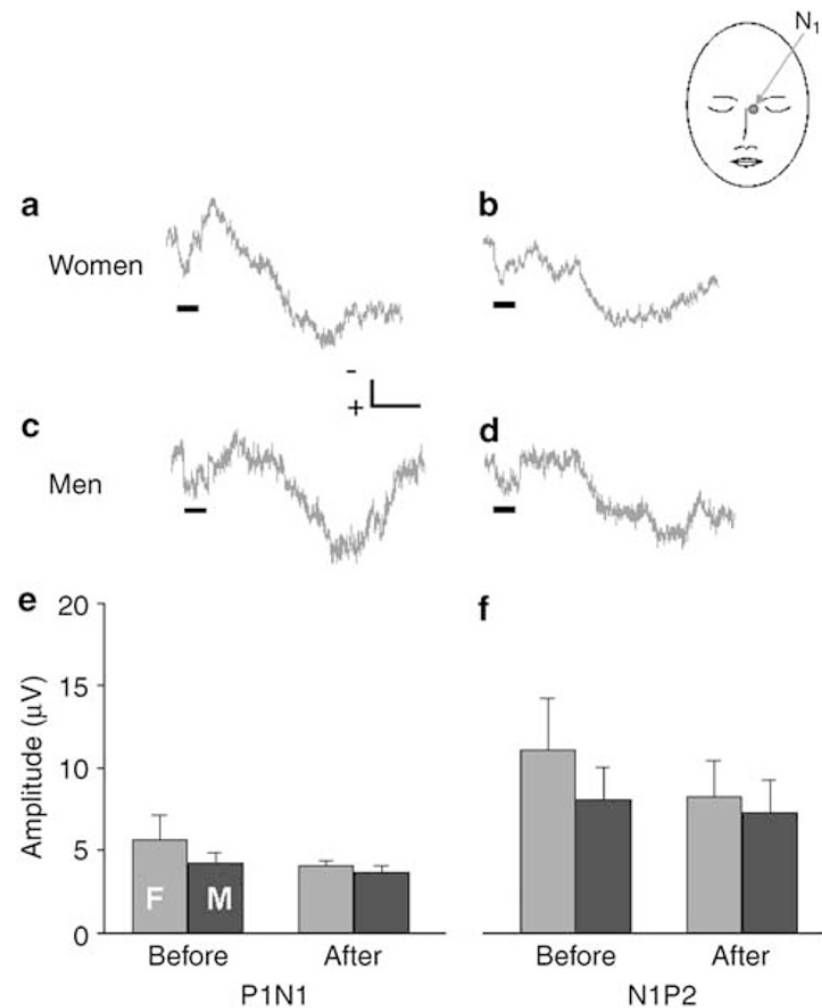

f

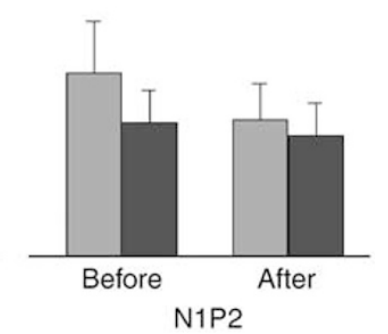

Figure 6 Benzaldehyde EOG. Ensemble averages of evoked potentials recorded from the nasion (see the inset diagram) in women $(n=5)$ and men $(n=5)$, in response to benzaldehyde stimulation recorded before (a and $c$ ) and after (b and d) sniff-training with benzaldehyde. The solid bar indicates the $200 \mathrm{~ms}$ stimulus pulse of benzaldehyde and the scale bar represents $2 \mu \vee$ (vertical) and $500 \mathrm{~ms}$ (horizontal) - clinical neurophysiological convention is followed and upward deflection is negative. The histograms represent the averages of the amplitudes of PINI (e) and NIP2 ( $f$ ) of individual responses from women and men before and after sniff-training. No significant changes were observed.

vertex to olfactory stimulation is sometimes referred to as the chemosensory (olfactory) event-related potential (CSERP or OERP) (Evans et al, 1993) and includes contributions from the peripheral olfactory system - the so-called exogenous components - as well as more central structures in the brain referred to as endogenous components. Recordings from the nasion have been shown to be correlated with the olfactory-evoked potential (EOG) recorded from the surface of the olfactory epithelium (Wang et al, 2004b). The EOG elicited by a brief $(0.2-1.0 \mathrm{~s})$ stimulus is a biphasic polarization with a duration of around $2-3 \mathrm{~s}$ in mice (Wang et al, 1993) and humans (Wang et al, 2004a, b). We show that the evoked potential recorded at the nasion increases in amplitude following the sniff-training with androstadienone. There is a marked, $72 \%$ increase in the N1P2 component of the EOG (Figure 1a and b) and there are concomitant changes in the OERP recorded at the vertex. The early, exogenous components, of the OERP reflect the external stimulus and various studies have demonstrated that the N1P2 amplitude is dependent upon the stimulus concentration (Kobal and Hummel, 1991; Tateyama et al, 1998; Wang et al, 2002). The later positive components (1000-1500 ms poststimulus) are thought to reflect cognitive operations (Rösler et al, 1986; Vergeler, 


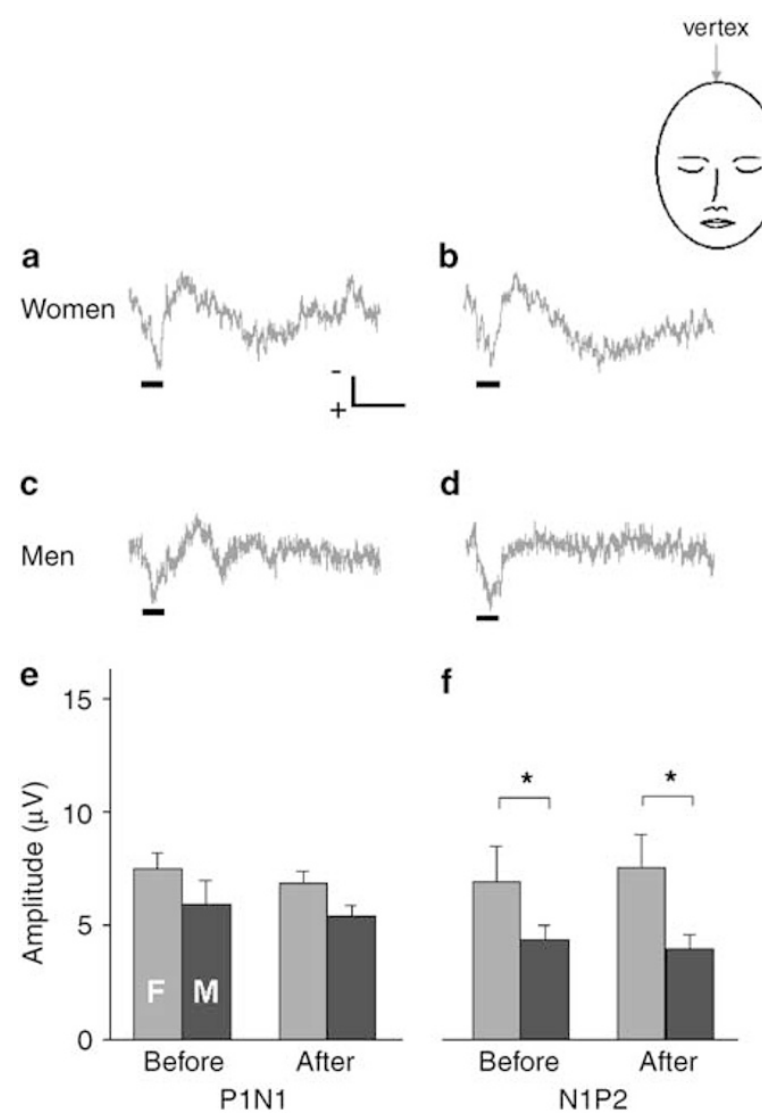

Figure 7 Benzaldehyde OERP. Ensemble averages of evoked potentials recorded from the vertex (see inset diagram) in women $(n=5)$ and men $(n=5)$, in response to benzaldehyde stimulation recorded before (a and c) and after ( $b$ and $d$ ) sniff-training with benzaldehyde. The solid bar indicates the 200 ms stimulus pulse of benzaldehyde and the scale bar represents $2 \mu \vee$ (vertical) and $500 \mathrm{~ms}$ (horizontal) - clinical neurophysiological convention is followed and upward deflection is negative. The histograms represent the averages of the amplitudes of PINI (e) and NIP2 (f) of individual responses from women and men before and after sniff-training. Significant (*) gender differences were observed for the P2 peak but no changes were observed following sniff-training.

1988; Pause and Krauel, 2000). We show that there are increases in both the early (P1N1) and late (N1P2) components of the OERP (Figure $1 \mathrm{e}$ and $\mathrm{d}$ ), with a pronounced increase in the first positive peak (P1). The sniff-training with androstadienone induces a large decrease in detection threshold, and this increase in P1 and the increase in the EOG may reflect an increase in the polarization of the olfactory epithelium, which could be caused by an increase in the number of receptor cells or the number of receptors expressed per cell. The change in the perception of androstadienone, from pleasant to unpleasant, that accompanies this sensitization (Figure 3) suggests that, rather than an increase in the numbers of receptors per cell which would only serve to increase the gain of the response, there is an increase in the contribution of a second perceptual channel, perhaps a second population of receptor cells, mediating the hedonic shift. Whether androstadienone contributes to the natural body odor is unknown but unlikely. It is relevant to consider that there were $1.23 \mathrm{mmol}$ of androstadienone in the highest concentration sample bottle for the threshold testing and there are only $228 \mathrm{pmol}$ in total in a human axilla (Nixon et al, 1988) - that is, there is $5.4 \times 10^{6}$ times less androstadienone in the axilla. The mean threshold for androstadienone following sensitization (lowest detectable dilution) was the bottle containing $2.4 \times 10^{-6} \mathrm{~mol}-$ four orders of magnitude greater than the amount in the axilla. It is therefore highly unlikely that the perceptual shifts in response to androstadienone would be detected consciously.

There are marked gender differences both in the response evoked by androstadienone stimulation and in the changes in response following experience-dependent sensitization, in spite of the fact that both men and women exhibited the same decrease in detection threshold and hedonic shift. The major changes in the evoked potential responses were seen in the early positive peak (P1) of the OERP in both men and women-perhaps reflecting changes at the receptor level related to an increase in sensitivity - and in the later stages of the EOG and OERP in women. These latter changes may reflect changes in cognitive processing that are restricted to women. Psychological changes occurring only in women have been reported in response to androstadienone exposure (Bensafi et al, 2003; Jacob and McClintock, 2000; Lundström and Olson, 2005).

Although there are gender differences in response to a nonsteroid odorant, benzaldehyde, these are restricted to the late positive component in the EOG and do not change following repetitive exposure. Neither was there any change in sensitivity or perceptual hedonics. The changes in sensitivity observed by Dalton et al (2002) to benzaldehyde in women of reproductive age are not therefore the same as the changes we observe in response to androstadienone exposure and it is likely that the benzaldehyde sensitization is related to higher level learning and more effective test-taking strategy employed by such women. We must therefore disagree with the statement by Dalton et al (op. cit.) that induction of enhanced olfactory sensitivity seems to be a more general phenomenon...' and conclude that, according to our current understanding, this phenomenon seems to be restricted to steroids.

If this phenomenon of sensory inconstancy applied more generally in the olfactory system, then to misquote Shakespeare, 'A rose at any other time would not smell the same.' Objects would change their odor characteristics from occasion-to-occasion and one function of the olfactory system, that of recognition, would fail. So what is the significance of such a phenomenon? Androstadienone is a steroid found in plasma in higher concentrations in men than in women (Brooksbank et al, 1972). It has been shown to cause gender-specific activation of the hypothalamus (Savic et al, 2001) and might therefore be expected to induce an endocrine response in women. Steroids are not very volatile and so close contact is required to be exposed to androstadienone in situ. This kind of proximity would be restricted to mothers and infants and sexual partners. The close contact maintained would result in sensitization and an enhanced response, the consequences of which are unknown and require further study. However, such properties would be exactly those one would expect of a biological signaling molecule.

In conclusion, we show that repetitive exposure to the steroid androstadienone causes decreased detection thresholds in men and women. Accompanying this sensitization 
was a shift in perception of the odor from pleasant to unpleasant and an increase in the evoked potentials recorded at the nasion and the vertex. Exposure-dependent increases in the early phase of the waveform, probably related to an increase in receptors, occur in both women and men, but changes in the later components, often associated with cognitive processing, occurred only in women. It is suggested that this type of anomalous sensory behavior of response inconstancy would be expected of a biological signaling molecule.

\section{REFERENCES}

Amoore JE (1977). Specific anosmias and the concept of primary odors. Chem Senses Flavor 2: 267-281.

Barlow HB (1982). General principles: the senses considered as physical instruments. In: Barlow HB, Mollon JD (eds). The Senses. Cambridge University Press: Cambridge. pp 1-34.

Bensafi M, Brown WM, Tsutsui T, Mainland JD, Johnson BN, Bremner EA et al (2003). Sex-steroid derived compounds induce sex-specific effects on autonomic nervous system function in humans. Behav Neurosci 117: 1125-1134.

Brooksbank BWL, Wilson DAA, MacSweeney DA (1972). The fate of androsta-4,16-dien-3-one and the origin of $3 \alpha$-hydroxy- $5 \alpha$ androst-16-ene in man. J Endocrinol 52: 239-251.

Dalton P, Doolittle N, Breslin PAS (2002). Gender-specific induction of enhanced sensitivity to odors. Nat Neurosci 5: 199-202.

Doty RL, Laing DG (2003). Psychophysical measurement of human olfactory function, including odorant mixture assessment. In: Doty RL (ed). Handbook of Olfaction and Gustation. Marcel Dekker: New York. pp 203-228.

Evans WJ, Kobal G, Lorig TS, Prah J (1993). Suggestions for collection and reporting of chemosensory (olfactory) eventrelated potentials. Chem Senses 18: 751-756.

Jacob S, McClintock MK (2000). Psychological state and mood effects of steroidal chemosignals in women and men. Horm Behav 37: 57-78.

Jacob TJC, Wang L, Jaffer S, McPhee S (2006). Changes in the odor quality of androstadienone during exposure-induced sensitization. Chem Senses 31: 3-8.

Kobal G, Hummel T (1991). Olfactory evoked potentials in humans. In: Getchell TV, Doty RL, Bartoschuk LM, Snow JB (eds). Smell and Taste in Health and Disease. Lippincott Williams and Wilkins: Philadelphia. pp 255-275.

Lundström JN, Olson M (2005). Subthreshold amounts of social odorant affect mood, but not behaviour, in heterosexual women when tested by a male, but not a female, experimenter. Biol Psychol 70: 197-204.

Mainland JD, Bremner EA, Young N, Johnson BN, Khan RM, Bensafi $\mathrm{M}$ et al (2002). One nostril knows what the other learns. Nature 419: 802.

Nixon A, Mallet AI, Gower DB (1988). Simultaneous quantification of the five odorous steroids (16-androstenes) in the axillary hair of men. J Steroid Biochem 29: 505-510.

Pause B, Krauel K (2000). Chemosensory event-related potentials (CSERP) as a key to the psychology of odors. Int J Psychophysiol 36: $105-122$.

Rösler F, Sutton S, Johnson R, Mulder G, Fabiani M, Gorsel EP et al (1986). Endogenous ERP components and cognitive constructs. A Review. In: McCallum WC, Zappoli R, Denoth F (eds). Cerebral Psychophysiology: Studies in Event-Related Potentials. Elsevier: Amsterdam. pp 51-93.

Savic I, Berglund H, Gulyas B, Roland P (2001). Smelling odorous sex hormone-like compounds causes sex-differentiated hypothalamic activations in humans. Neuron 31: 661-668.

Stevens DA, O'Connell RJ (1995). Enhanced sensitivity to androstenone following regular exposure to pemenone. Chem Senses 20: 413-419.

Tateyama T, Hummel T, Roscher S, Post H, Kobal G (1998). Relation of olfactory event-related potentials to changes in stimulus concentration. Electroenceph Clin Neurophysiol 108: 449-455.

Vergeler R (1988). Event-related potentials and cognition: a critique of the context updating hypothesis and an alternative interpretation of P3. Behav Brain Sci 11: 343-356.

Wang H-W, Wysocki CJ, Gold GH (1993). Induction of olfactory receptor sensitivity in mice. Science 260: 98-100.

Wang L, Chen L, Jacob TJC (2004a). Evidence for peripheral plasticity in human odour response. J Physiol 554: 236-244.

Wang L, Hari C, Jacob TJC (2004b). A new non-invasive method for recording the electro-olfactogram using external electrodes. Clin Neurophysiol 115: 1631-1640.

Wang L, Walker VE, Sardi H, Fraser C, Jacob TJC (2002). The correlation between physiological and psychological responses to odour stimulation in human subjects. Clin Neurophysiol 112: 542-551.

Wysocki CJ, Beauchamp GK (1984). Ability to smell androstenone is genetically determined. Proc Natl Acad Sci USA 81: 4899-4902.

Wysocki CJ, Dorries KM, Beauchamp GK (1989). Ability to perceive androstenone can be acquired by ostensibly anosmic people. Proc Natl Acad Sci USA 86: 7976-7978.

Yee KK, Wysocki CJ (2001). Odorant exposure increases olfactory sensitivity: olfactory epithelium is implicated. Physiol Behav 72: 705-711. 